\title{
Efeitos do Uso da Terra sobre a Produção Apícola com Destaque para Estágios Distintos de Floresta Ombrófila Mista
}

\author{
Mateus Ruginski Marochi ${ }^{1}$, Paulo Costa de Oliveira Filho², \\ Gabriela Schmitz Gomes ${ }^{3}$, Artur Lourival da Fonseca Machado ${ }^{4}$
}

\begin{abstract}
${ }^{1}$ Mestre em Ciências Florestais - Universidade Estadual do Centro-Oeste - UNICENTRO-PR, Irati/PR, Brasil ${ }^{2}$ Departamento de Engenharia Ambiental - Universidade Estadual do Centro-Oeste - UNICENTRO-PR, Irati/PR, Brasil ${ }^{3}$ Departamento de Engenharia Florestal, Universidade Estadual do Centro-Oeste - UNICENTRO-PR, Irati/PR, Brasil ${ }^{4}$ Departamento de Matemática, Universidade Estadual do Centro-Oeste - UNICENTRO-PR, Irati /PR, Brasil
\end{abstract}

\begin{abstract}
RESUMO
Este trabalho teve como objetivo identificar possíveis relações estatísticas entre o uso da terra do entorno de cinco apiários - composto por diversos pastos apícolas incluindo dois estágios de Floresta Ombrófila Mista, considerando diferentes raios de proximidade - e suas produções de mel. Foram utilizadas imagens orbitais do satélite SPOT com resolução espacial de cinco metros, para elaborar a classificação de uso da terra nas áreas de abrangência de cada apiário, empregando-se o método de classificação e interpretação por meio da vetorização sobre tela, além de trabalho de campo. Os dados obtidos foram relacionados à produção média de mel de cada apiário. Os resultados demonstraram que existem relações estatisticamente significativas entre as variações de uso da terra do entorno dos apiários, considerando-se diferentes raios de proximidade, e suas produções médias de mel.
\end{abstract}

Palavras-chave: produto florestal não madeireiro, flora apícola florestal, efeito da floresta na produção de mel.

\section{Effects of Land Use on Production of Beekeeping with Highlight for Different Stages of Araucaria Forest}

\begin{abstract}
This work aimed to identify relationships between the land use around five apiaries, composed by several bee pastures, including two stages of Araucaria Forest, for three different turning radii of surrounding areas and their honey yield. Were used SPOT satellite images with 5 meters spatial resolution to establish the land use classification, using the method of classification and interpretation through vectorization on screen and field work. The obtained data were related to the honey average yield, per apiary. The results demonstrated that there are significant statistical relationships between the different land uses around the apiaries, for different surrounding range areas, and their average honey yield.
\end{abstract}

Keywords: no-wood forest products, beekeeping forest flora, forest effect on honey production. 


\section{INTRODUÇÃO}

A atividade apícola é largamente difundida em todo o Brasil. No Estado do Paraná, trata-se de uma atividade tradicional, que tem sido bastante difundida entre pequenos produtores rurais como uma alternativa complementar de renda caracterizada como uso sustentável e não madeirável da floresta.

A pastagem ou flora apícola, nome dado ao conjunto de plantas que fornecem alimento às abelhas em uma determinada região, é um dos fatores determinantes para a eficiência da atividade apícola, seja qual for a localidade. A Apis mellifera, espécie de abelha mais explorada com finalidades econômicas no Brasil, procura concentrar esforços em poucas espécies vegetais, cujas floradas propiciem altos ganhos energéticos via néctar. A produção de mel está, portanto, diretamente associada à flora apícola, pois, além do volume produzido, a cor e o sabor do mel dependem da espécie botânica da qual o néctar foi extraído (Freitas, 1996).

A dimensão da flora apícola, assim como a sua qualidade, determina a capacidade de suporte da área, a qual irá determinar o número de colmeias locadas, levando-se em conta o aspecto produtivo. Dessa forma, o potencial florístico da área será explorado pelas abelhas, de forma a maximizar a produção, sem que ocorra competição pelos recursos disponíveis (Barbosa et al., 2007).

Conforme Wolf (2008), o sucesso da atividade apícola depende, entre outros fatores, da escolha do local adequado e da correta instalação das colmeias. Dentre os aspectos mais importantes que o local do apiário deve apresentar, destacam-se: uma boa flora apícola, água de boa qualidade, sombreamento para as colmeias, distância que permita segurança a pessoas e animais, e facilidade de acesso, entre outros.

Apesar de as abelhas terem a habilidade de forragear com alta eficiência em uma área distante ao redor do apiário (cerca de 700 ha de área total explorada), quanto mais próxima da colmeia estiver a fonte de alimento, mais rápido será o transporte. Tal proximidade permite um maior número de viagens, contribuindo para o aumento da produção, além de economizar energia necessária para os voos, o que se traduz em maior armazenamento nos favos (Wiese, 2000). Para Wolf (2008), estar próximo significa estar dentro de um raio máximo de $500 \mathrm{~m}$ a $1,5 \mathrm{~km}$.

Para se obter rendimentos excelentes, o local ideal é aquele onde a flora apícola (o conjunto de flores que fornecerão o pólen e o néctar às abelhas) esteja próxima, seja abundante e não apresente interrupções durante o ano. Segundo Pegoraro \& Ziller (2003), em um estudo realizado em União da Vitória-PR, em vegetação no estágio médio de sucessão vegetal da Floresta Ombrófila Mista, os valores de importância das árvores para a apicultura ultrapassaram as árvores do estágio sucessional avançado.

Segundo Rodrigues (2000), a análise do uso e da cobertura da terra, por meio de informações obtidas pelo sensoriamento remoto, é de grande utilidade para o planejamento e a administração da ocupação ordenada e racional do meio físico, além de possibilitar avaliar e monitorar a preservação de áreas de vegetação natural.

Este trabalho tem como objetivo estabelecer possíveis relações entre o uso da terra do entorno de cinco apiários, composto por diversos pastos apícolas, considerando-se diferentes raios de proximidade, e suas produções de mel. Este trabalho se justifica pela importância de se conhecerem cada vez mais as condições ambientais que favorecem as melhores produtividades dos apiários, em função dos seus entornos e respectivos pastos apícolas. Da mesma forma, também se justifica pela valorização da apicultura como alternativa sustentável e não madeirável da floresta. Ressalta-se ainda que esta metodologia pode ser aplicada para identificação de áreas com potencial apícola.

A técnica estatística utilizada foi a Análise de Agrupamentos (Cluster Analysis), que é uma importante técnica exploratória, embora sem suposições sobre o número de grupos ou a estrutura de agrupamentos. $\mathrm{O}$ agrupamento é feito com base em similaridades ou distâncias (dissimilaridades).

$\mathrm{Na}$ análise de agrupamentos, a similaridade entre duas amostras pode ser expressa como uma função da distância entre os dois pontos representativos destas amostras no espaço $\mathrm{n}$-dimensional. A maneira mais usual de calcular a distância entre dois pontos A e 
B, no espaço n-dimensional, é a distância euclidiana $\left(\mathrm{x}_{\mathrm{AB}}\right)$, dada pela expressão (Equação 1):

$$
x_{A B}=\sqrt{\sum_{j=1}^{n}\left(d_{A j}-d_{B j}\right)^{2}}
$$

em que: $d_{A j}$ e $d_{B j}=j$-ésimas coordenadas dos pontos A e B.

A técnica de agrupamento hierárquico (Hierarchical Analysis ou Cluster Analysis) interliga as amostras por suas associações, produzindo um dendrograma no qual as amostras semelhantes, segundo as variáveis escolhidas, são agrupadas entre si. A suposição básica de sua interpretação é esta: quanto menor a distância entre os pontos, maior a semelhança entre as amostras. Os dendrogramas são especialmente úteis na visualização de semelhanças entre amostras ou objetos representados por pontos em espaço com dimensão maior do que três, em que a representação de gráficos convencionais não é possível (Moita Neto \& Moita, 1998).

Existem muitas maneiras de procurar agrupamentos no espaço n-dimensional. A maneira matematicamente mais simples consiste em agrupar os pares de pontos que estão mais próximos, usandose a distância euclidiana, e substituí-los por um novo ponto localizado na metade da distância entre estes. Tal procedimento, quando repetido até que todos os pontos sejam agrupados em um só ponto, leva à construção do dendrograma, em cujo eixo horizontal são colocadas as amostras e, no eixo vertical, o índice de similaridade $s_{i j}$ entre os pontos i e j, calculado segundo a seguinte expressão (Equação 2):

$s_{i j}=1-\frac{d_{i j}}{d_{\text {máx }}}$

em que: $d_{i j}=$ distância entre os pontos $\mathrm{i}$ e j; $\mathrm{d}_{\text {máx }}=$ distância máxima entre qualquer par de pontos.

Os dendrogramas, portanto, consistem em diagramas que representam a similaridade entre pares de amostras (ou grupos de amostras), numa escala que vai de um (identidade) a zero (nenhuma similaridade) (Moita Neto \& Moita, 1998).

\section{MATERIAL E MÉTODOS}

\section{1. Área do estudo}

O trabalho foi desenvolvido nos municípios da região Centro-Sul do Estado do Paraná (Figura 1).

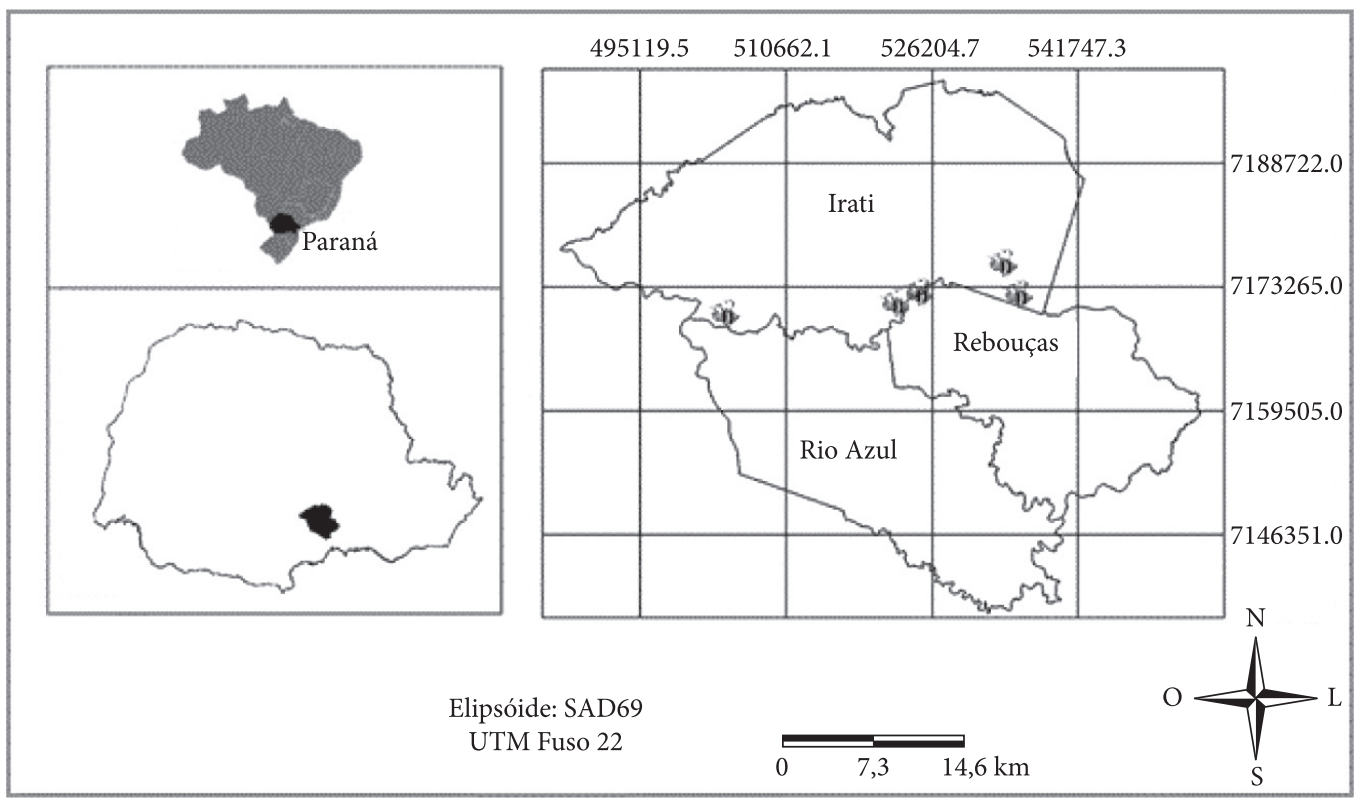

Figura 1. Área de Estudo com os cinco apiários, sendo quatro no município de Irati-PR, e um no município de Rebouças-PR.

Figure 1. Study Area with 5 apiaries, 4 in the municipality of Irati, and 1 in municipality of Rebouças-PR. 
Dos cinco apiários, quatro estão no município de Irati e um no município de Rebouças. A região apresenta, segundo a classificação de Köppen, clima tipo Cfb (temperado), com verões amenos, invernos com ocorrências de geadas severas e frequentes, sem ocorrência de estação seca. As médias mensais de precipitação pluviométrica e da umidade relativa do ar são $193,97 \mathrm{~mm}$ e 79,58\%, respectivamente. Os apiários fazem parte do projeto de extensão promovido pelo Laboratório de Agrossilvicutura do Departamento de Engenharia Florestal, da Universidade Estadual do Centro-Oeste, campus de Irati, Paraná, que busca desenvolver os fomentados por meio da atividade apícola, auxiliando com os equipamentos, as caixas e a assistência técnica.

Para a caracterização dos pastos apícolas encontrados nas proximidades dos apiários, foram utilizados os seguintes materiais: ortoimagens fusionadas e multiespectrais de resolução espacial de cinco metros do satélite SPOT 5, obtidas em 2006, abrangendo a área do estudo, e ambiente de sistema de informações geográficas SPRING versão 5.06. O georreferenciamento dos apiários, bem como os trabalhos em campo, foram realizados com uso de um receptor de DGPS marca Trimble, modelo Pro Xt, e, para o pós-processamento, utilizou-se o aplicativo Pathfinder Office.

A seguir, as coordenadas de localização dos cinco apiários, que foram espacializadas sobre o mosaico da composição colorida das ortoimagens. Utilizouse o aplicativo SPRING tanto para os trabalhos de interpretação de imagens, vetorização e associação a classes, como também para as operações e a construção dos mapas de distâncias (zonas tampão ou buffers zone).

Conforme procedimentos realizados em Wolf (2008), foi definido um raio máximo de estudo de 1.500 metros a partir do centro de cada apiário. Além disso, foram consideradas também as distâncias de 500 e 1000 de cada um dos cinco apiários. Desta forma, foram definidas zonas tampão com distâncias de 500, 1000 e 1500 metros em torno de cada apiário (Figura 2).

Posteriormente, foram utilizadas as zonas tampão de 1500 metros como máscara de corte para a definição das áreas para a interpretação na imagem. Cada área de influência dos cinco apiários foi interpretada visualmente e classificada por meio de interpretação visual e vetorização sobre tela, seguidas de associação à classe no ambiente SIG dos polígonos vetorizados.

Foram definidas as seguintes classes: i) agricultura ou solo exposto; ii) estágio inicial da Floresta Ombrófila Mista (FOM); iii) estágio secundário da FOM; iv) área de Pinus sp.; v) área de Eucalyptus sp., e vi) área urbana. A seguir, foram obtidas automaticamente as áreas das coberturas ou classes expressas em hectares, considerando-se os raios de 500, 1000 e 1500 metros de zonas tampão.

O manejo e a coleta do mel foram semelhantes nos cinco apiários. As coletas foram realizadas entre 20 de novembro de 2010 e 15 de março de 2011, sendo este o período de safra anual apícola na região. Todo o mel foi pesado e processado no Laboratório de Agrossilvicultura do Departamento de Engenharia Florestal da UNICENTRO.

O processamento do mel foi realizado no Laboratório de Processamento de Mel do Departamento de Engenharia Florestal da Universidade Estadual do Centro-Oeste/ UNICENTRO-PR.

Em função dos tipos variáveis e do número limitado de repetições, o método que mais se adaptou ao estudo foi o de análise multivariada de agrupamentos (Cluster analysis), baseado na distância euclidiana. Este método foi, portanto,

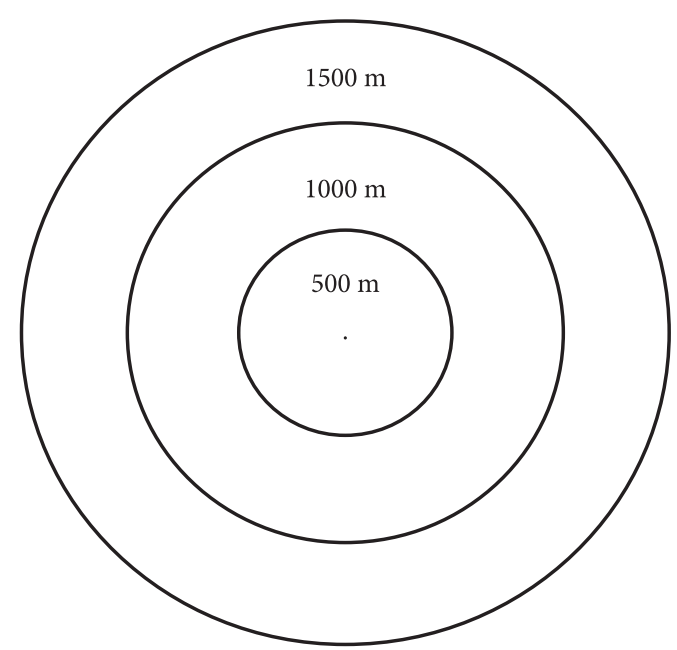

Figura 2. Zonas tampão definidas a partir do centro de cada apiário.

Figure 2. Buffer zone from the center of each apiary. 
utilizado para realizar as análises com o objetivo de identificar relações entre as classes de uso da terra contendo diversos pastos apícolas, inclusive os florestais, e os valores médios de produção dos apiários.

Esta técnica foi utilizada visando a entender a natureza complexa das relações multivariadas, com agrupamento dos itens (apiários), por meio da identificação de uma estrutura natural de agrupamento.

Neste trabalho, foi utilizado o aplicativo estatístico Statgraphics Centurion. As variáveis utilizadas foram a produção média por colmeia e os diversos níveis de usos da terra que contém pastos apícolas para três diferentes distâncias ou raio de proximidade de ação dos apiários; estas variáveis foram inseridas no programa com os seguintes códigos (Tabela 1).

\section{RESULTADOS E DISCUSSÃO}

Após aplicação da técnica para o estabelecimento das zonas tampão, foram obtidos os raios de proximidade, $0-500 \mathrm{~m}, 500-1000 \mathrm{~m}, 1000-1500 \mathrm{~m}$, os quais possuem diferentes tamanhos de áreas, conforme a Tabela 2.

Tabela 1. Variáveis utilizadas no processo estatístico. Table 1. Variables used in statistical process.

\begin{tabular}{ll}
\hline Código & \multicolumn{1}{c}{ Variável } \\
\hline PMMC & Produção média por colmeia \\
\hline E500 & Eucalyptus sp. a $500 \mathrm{~m}$ \\
\hline E1000 & Eucalyptus sp. a $1000 \mathrm{~m}$ \\
\hline E1500 & Eucalyptus sp. a $1500 \mathrm{~m}$ \\
\hline AG500 & Agricultura/Solo Exposto a $500 \mathrm{~m}$. \\
\hline AG1000 & Agricultura/Solo Exposto a $1000 \mathrm{~m}$ \\
\hline AG1500 & Agricultura/Solo Exposto a $1500 \mathrm{~m}$ \\
\hline FI500 & FOM $^{*}$, estágio inicial a $500 \mathrm{~m}$ \\
\hline FI1000 & FOM $^{*}$, estágio inicial a $1000 \mathrm{~m}$ \\
\hline FI1500 & FOM $^{*}$, estágio inicial a $1500 \mathrm{~m}$ \\
\hline FS500 & FOM $^{*}$, estágio secundário a $500 \mathrm{~m}$ \\
\hline FS1000 & FOM , estágio secundário a $1000 \mathrm{~m}$ \\
\hline FS1500 & FOM , estágio secundário a $1500 \mathrm{~m}$ \\
\hline P500 & Pinus sp. a $500 \mathrm{~m}$ \\
\hline P1000 & Pinus sp. a $1000 \mathrm{~m}$ \\
\hline P1500 & Pinus sp. a $1500 \mathrm{~m}$ \\
\hline AU500 & Área urbana a $500 \mathrm{~m}$ \\
\hline AU1000 & Área urbana a $1000 \mathrm{~m}$ \\
\hline AU1500 & Área urbana a $1500 \mathrm{~m}$ \\
\hline$*$ FOM Floresta Ombrófila Mista \\
\hline
\end{tabular}

Os resultados das classificações de uso da terra (Figura 3) foram obtidos por meio de trabalhos de interpretação e vetorização sobre tela, e expressos em hectares de acordo com os raios de proximidade (Tabelas 3 a 7). Não foi verificada a existência de todas as classes de uso da terra na área dos cinco apiários, sendo algumas presentes somente em determinadas áreas. A seguir, foi realizada a análise descritiva dos
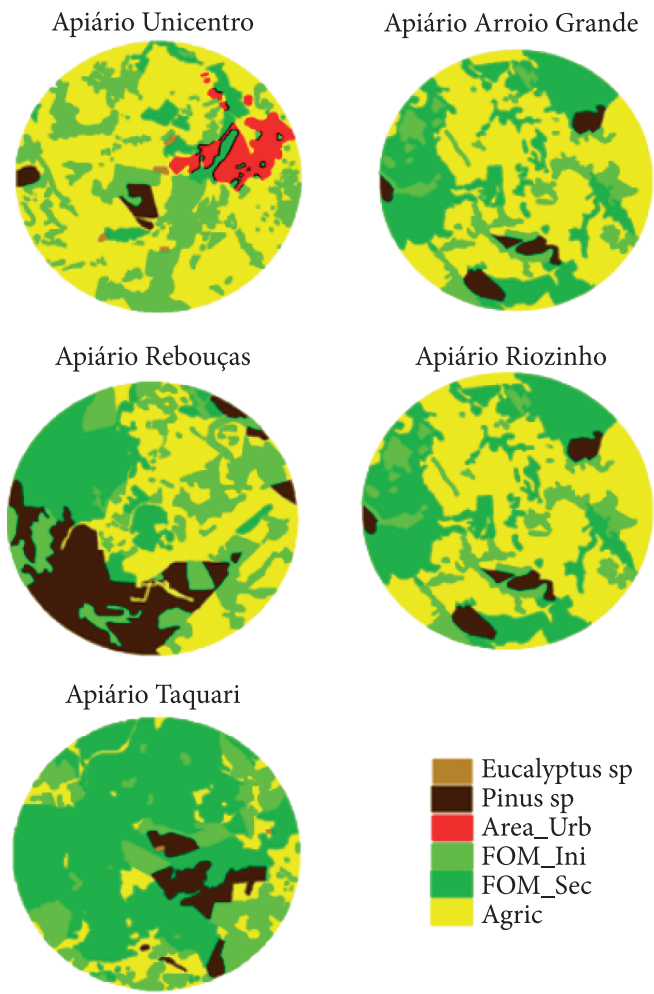

Figura 3. Classificação do uso da terra no entorno de $1500 \mathrm{~m}$ de cada apiário.

Figure 3. Classification of land use around $1500 \mathrm{~m}$ in each apiary.

Tabela 2. Áreas de influência (em hectares) dos apiários determinadas pelos raios de proximidade (metros) definidos pelas zonas tampão.

Table 2. Influential areas (in hectares) on apiaries determined by the proximity rays (in meters) defined for the buffer zones.

\begin{tabular}{cc}
\hline Buffers $(\mathbf{m})$ & Área (ha) \\
\hline $0-500$ & 78,53 \\
$500-1000$ & 235,61 \\
$1000-1500$ & 392,69 \\
Total & 706,85 \\
\hline
\end{tabular}


Tabela 3. Áreas (ha) dos usos da terra do apiário UNICENTRO.

Table 3. Areas (ha) of land uses apiary UNICENTRO.

\begin{tabular}{|c|c|c|c|c|}
\hline $\begin{array}{c}\text { Apiário } \\
\text { UNICENTRO }\end{array}$ & $\begin{array}{c}0-500 \\
(\mathrm{~m})\end{array}$ & $\begin{array}{c}500-1000 \\
(\mathrm{~m})\end{array}$ & $\begin{array}{c}1000-1500 \\
(\mathrm{~m})\end{array}$ & Visualização \%/Total \\
\hline Agricultura/Solo Exposto & 30,83 & 152,23 & 272,80 & \\
\hline FOM - Estágio Inicial & 25,49 & 40.81 & 77,98 & \\
\hline FOM - Estágio Secundário & 6,08 & 21,37 & 15,63 & FOM sec. \\
\hline Pinus sp. & 9,60 & 1,49 & 4,57 & $\begin{array}{l}\text { Pinus sp } \\
\text { A. Urban }\end{array}$ \\
\hline Área Urbana & 4,18 & 18,24 & 21,69 & $\begin{array}{l}\text { A. Urban } \\
\text { Eucalyptus sp }\end{array}$ \\
\hline Eucalyptus sp. & 2,32 & 1,44 & & \\
\hline Total & 78,53 & 235,61 & 392,69 & 706,85 \\
\hline
\end{tabular}

Tabela 4. Áreas (ha) dos usos da terra no apiário Arroio Grande.

Table 4. Areas (ha) of land uses in Arroio Grande apiary.

\begin{tabular}{|c|c|c|c|c|}
\hline $\begin{array}{c}\text { Apiário } \\
\text { Arroio Grande }\end{array}$ & $\begin{array}{c}0-500 \\
(\mathrm{~m})\end{array}$ & $\begin{array}{c}500-1000 \\
(\mathrm{~m})\end{array}$ & $\begin{array}{c}1000-1500 \\
(\mathrm{~m})\end{array}$ & Visualização \%/Total \\
\hline Agricultura/Solo Exposto & 59,23 & 124,92 & 172,85 & \multirow{5}{*}{$\begin{array}{l}\text { Agricul./ S } \\
\text { FOM ini. } \\
\text { FOM sec. } \\
\text { Pinus sp }\end{array}$} \\
\hline FOM - Estágio Inicial & 19,30 & 9,52 & 148,69 & \\
\hline FOM - Estágio Secundário & & 92,36 & 38,39 & \\
\hline Pinus sp. & & 8,80 & 32,75 & \\
\hline Total & 78,53 & 235,61 & 392,69 & \\
\hline
\end{tabular}

Tabela 5. Áreas (ha) dos usos da terra apiário Rebouças.

Table 5. Areas (ha) of land uses Rebouças apiary.

\begin{tabular}{|c|c|c|c|c|}
\hline $\begin{array}{c}\text { Apiário } \\
\text { Rebouças }\end{array}$ & $\begin{array}{c}0-500 \\
(\mathrm{~m})\end{array}$ & $\begin{array}{c}500-1000 \\
(\mathrm{~m})\end{array}$ & $\begin{array}{c}1000-1500 \\
(\mathrm{~m})\end{array}$ & Visualização \%/Total \\
\hline Agricultura/Solo Exposto & 49,86 & 85,84 & 118,63 & \multirow{4}{*}{$\begin{array}{l}\text { Agricul./ Solo expost. } \\
\text { FOM ini. } \\
\text { FOM sec. } \\
\text { Pinus sp }\end{array}$} \\
\hline FOM - Estágio Inicial & 11,60 & 32,54 & 103,03 & \\
\hline FOM - Estágio Secundário & 17,06 & 56,55 & 70,83 & \\
\hline Pinus sp. & & 60,66 & 100,18 & \\
\hline Total & 78,53 & 235,61 & 392,69 & 706,85 \\
\hline
\end{tabular}

Tabela 6. Áreas dos usos da terra apiário Riozinho.

Table 6. Areas of land uses apiary Riozinho.

\begin{tabular}{|c|c|c|c|c|}
\hline $\begin{array}{l}\text { Apiário } \\
\text { Riozinho }\end{array}$ & $\begin{array}{c}0-500 \\
(\mathrm{~m})\end{array}$ & $\begin{array}{c}500-1000 \\
(\mathrm{~m})\end{array}$ & $\begin{array}{c}1000-1500 \\
(\mathrm{~m})\end{array}$ & Visualização \%/Total \\
\hline Agricultura/Solo Expost & 57,75 & 160,96 & 170,30 & Agricul./ Solo expost. \\
\hline FOM - Estágio Inicial & 5,82 & 24,97 & 40,21 & FOM ini. \\
\hline FOM - Estágio Secundário & 14,95 & 38,07 & 162,92 & FOM sec. \\
\hline Pinus sp. & & 11,60 & 19,25 & \\
\hline Total & 78,53 & 235,61 & 392,69 & 706,85 \\
\hline
\end{tabular}


Tabela 7. Áreas dos usos da terra apiário Taquari.

Table 7. Areas of land uses apiary Taquari.

\begin{tabular}{|c|c|c|c|c|}
\hline $\begin{array}{l}\text { Apiário } \\
\text { Taquari }\end{array}$ & $\begin{array}{c}0-500 \\
(\mathrm{~m})\end{array}$ & $\begin{array}{c}500-1000 \\
(\mathrm{~m})\end{array}$ & $\begin{array}{c}1000-1500 \\
(\mathrm{~m})\end{array}$ & Visualização \%/Total \\
\hline Agricultura/Solo Exposto & 8,62 & 15,52 & 104,64 & \\
\hline FOM - Estágio Inicial & 13,51 & 11,10 & 86,46 & \\
\hline FOM - Estágio Secundário & 37,03 & 192,65 & 191,52 & FOM sec. \\
\hline Pinus sp. & 18,95 & 16,33 & 9,73 & Pinus sp \\
\hline Eucalyptus sp. & 0,40 & & 0,32 & \\
\hline Total & 78,53 & 235,61 & 392,69 & 706,85 \\
\hline
\end{tabular}

resultados de uso e cobertura da terra encontrados no trabalho de interpretação e classificação. A tabela 8 apresenta a produção mel dos apiários utilizados na pesquisa

No apiário UNICENTRO, a classe agricultura/ solo exposto apresenta o maior percentual, 58\% do entorno, distribuído nas três áreas de proximidade com destaque para a faixa de $1000 \mathrm{~m}$ a $1500 \mathrm{~m}$, dentro da qual ocupa $69,47 \%$. A segunda classe mais frequente neste apiário foi a Floresta Ombrófila Mista (FOM) estágio inicial, com 20,41\% do total da área de proximidade, com destaque para os primeiros $500 \mathrm{~m}$, área na qual representa 32,47\%. As classes - Floresta Ombrófila Mista (FOM) estágio secundário e Pinus sp. - ocorrem com menor frequência, respectivamente, $6,09 \%$ e 2,22\%. No entorno deste apiário, destaca-se a ocorrência das classes Área Urbana e Eucalyptus sp., em especial a segunda, por estar localizada na faixa dos primeiros $500 \mathrm{~m}$ e pelo seu grande potencial apícola.

No apiário Arroio Grande, a classe agricultura/ solo exposto apresenta o maior percentual, 57\% do entorno, distribuído nas três áreas de proximidade, com destaque para a faixa de até $500 \mathrm{~m}$, dentro da qual ocupa $75,42 \%$. A segunda classe mais frequente neste apiário foi a Floresta Ombrófila Mista (FOM) estágio inicial, com $22,16 \%$ do total da área de proximidade, com destaque para a faixa de $1000 \mathrm{~m}$ a $1500 \mathrm{~m}$, área na qual representa $37,86 \%$. As classes Floresta Ombrófila Mista (FOM) estágio secundário e Pinus sp. representam, respectivamente, 16,33\% e $4,0 \%$, e são encontradas na faixa de $500 \mathrm{~m}$ a $1500 \mathrm{~m}$.

No apiário Rebouças, a classe agricultura/solo exposto apresenta o maior percentual, $43 \%$ do entorno, distribuído nas três áreas de proximidade, com destaque para a faixa de até $500 \mathrm{~m}$, dentro da
Tabela 8. Produção de mel dos apiários utilizados neste trabalho

Table 8. Production of honey from apiaries used in this work.

\begin{tabular}{clrcc}
$\mathbf{N}$ & \multicolumn{1}{c}{ Apiário } & PAM & NC & PMMC \\
1 & Unicentro & 126,45 & 8 & 15,80 \\
2 & Arroio Grande & 12,20 & 2 & 6,10 \\
3 & Rebouças & 18,30 & 4 & 4,57 \\
4 & Riozinho & 48,45 & 5 & 9,69 \\
5 & Taquari & 110,48 & 11 & 10,04 \\
\hline
\end{tabular}

PAM: Produção Anual de Mel (kg); NC: Número de Colmeias; PMMC: Produção Média por Colmeia (kg).

qual ocupa $63,49 \%$. A segunda classe mais frequente neste apiário foi a Floresta Ombrófila Mista (FOM) estágio secundário, com $21,25 \%$ do total da área de proximidade, com destaque para a faixa entre 500 m e 1000 m, área na qual representa 24\%. A classe Pinus sp. apresentou uma frequência de 17,09\%, a maior em comparação aos outros apiários. A Floresta Ombrófila Mista (FOM) estágio inicial apresentou uma cobertura de 18,27\% do total da área de proximidade, destacando a faixa de $1000 \mathrm{~m}$ a $1500 \mathrm{~m}$.

No apiário Riozinho, a classe agricultura/solo exposto apresenta o maior percentual, 61,74\% do entorno, distribuído nas três áreas de proximidade, com destaque para a faixa de $1000 \mathrm{~m}$ a $1500 \mathrm{~m}$, dentro da qual ocupa $69,47 \%$. A segunda classe mais frequente neste apiário foi a Floresta Ombrófila Mista (FOM) estágio secundário, com 25,56\% do total da área de proximidade, com destaque para a faixa de $1000 \mathrm{~m}$ a $1500 \mathrm{~m}$, área na qual representa 41,49\%. As classes Floresta Ombrófila Mista (FOM) estágio Inicial e Pinus sp. ocorrem com frequência menor, respectivamente, $9,42 \%$ e 3,28\%. 
No apiário Taquari, a classe Floresta Ombrófila Mista (FOM) estágio secundário apresenta o maior percentual, $43 \%$ do entorno, distribuído nas três áreas de proximidade, com destaque para a faixa de $500 \mathrm{~m}$ a $1000 \mathrm{~m}$, dentro da qual ocupa 81,77\%. A segunda classe mais frequente neste apiário foi a agricultura/solo exposto, com $14,74 \%$ do total da área de proximidade, com destaque para a faixa entre 1000 m e 1500 m, área na qual representa 26,65\%. A Floresta Ombrófila Mista (FOM) estágio inicial apresentou uma cobertura de $14,64 \%$ do total do raio de proximidade, destacando a faixa de 1000 m a $1500 \mathrm{~m}$, da qual representa $22,02 \%$. A classe Pinus sp. apresentou uma frequência de $11,18 \%$. A classe Eucalyptus sp. representa 0,51\% da área e está localizada, na sua maioria, na faixa dos primeiros $500 \mathrm{~m}$.

Para identificar as possíveis relações entre a variável produção média de mel por colmeia e as diferentes variáveis de uso da terra, procedeu-se à classificação pela técnica de análise de agrupamentos. A Tabela 9 apresenta os centroides calculados para as variáveis, considerando os cinco locais (apiários) agrupados em um único cluster.

Foram realizadas duas análises: a primeira, considerando somente as variáveis de uso da terra para os raios de proximidade dos apiários, sem

Tabela 9. Centroides para um cluster considerando os cinco apiários.

Table 9. Centroid cluster for all five apiaries.

\begin{tabular}{|lccc|}
\hline \multicolumn{4}{c|}{ Clusters } \\
\hline \multicolumn{1}{|c}{ Classe } & $\mathbf{5 0 0} \mathbf{~ m}$ & $\mathbf{1 0 0 0} \mathbf{~ m}$ & $\mathbf{1 5 0 0} \mathbf{~ m}$ \\
\hline Agricultura/Solo Exposto & 41,2628 & 107,898 & 167,848 \\
\hline Área Urbana & 0,83742 & 3,64858 & 4,3398 \\
\hline FOM - Estágio Secundário & 15,0308 & 80,2061 & 95,8651 \\
FOM - Estágio Inicial & 15,1498 & 23,7951 & 91,2799 \\
Pinus sp. & 5,71232 & 19,7822 & 33,3006 \\
Eucalyptus sp. & 0,54664 & 0,28966 & 0,0658 \\
\hline Prod. Média/Colmeia & & 9,24298 \\
\hline
\end{tabular}

considerar as variáveis de produção média de mel por apiário. Após a aplicação da técnica de agrupamentos para os dados no aplicativo Statgraphics, foram obtidas as distâncias e construídos os clusters, conforme a Tabela 10. Segue, então, a Figura 4, que apresenta o dendrograma da análise de agrupamento sem considerar as variáveis de produção de mel.

Uma segunda análise de agrupamento foi realizada considerando-se as variáveis de produção

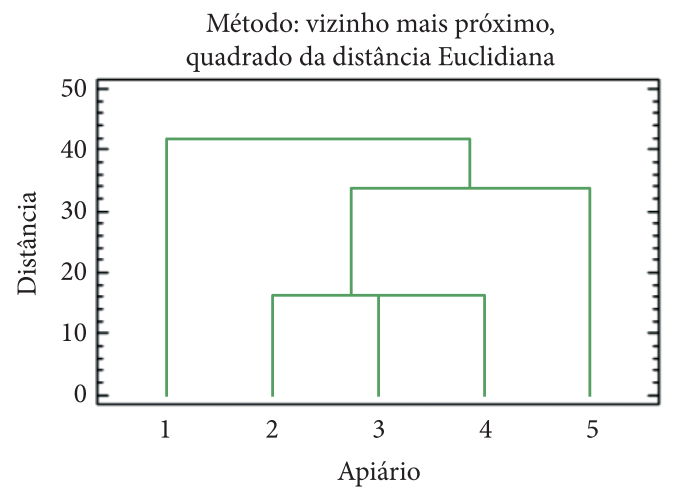

Figura 4. Dendrograma da análise de agrupamento sem considerar a variável produção de mel.

Figure 4. Dendrogram of cluster analysis without considering honey production variable.

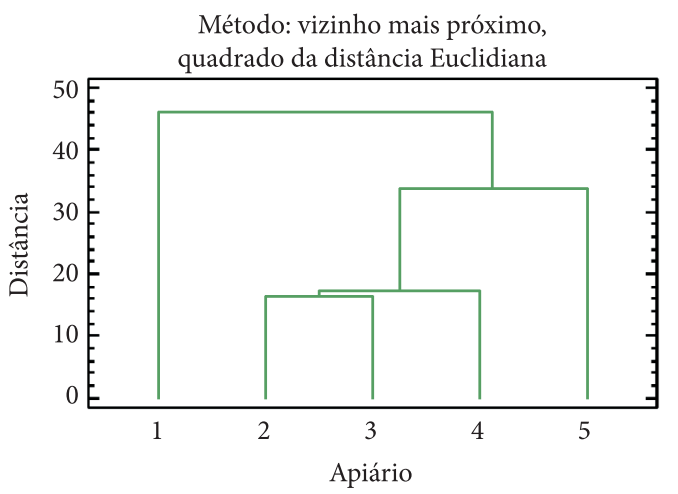

Figura 5. Dendrograma da Análise de Agrupamento incluindo a produção de mel.

Figure 5. Dendrogram of cluster analysis including the honey production variable.

Tabela 10. Análise de agrupamento sem considerar as variáveis de produção de mel.

Table 10. Cluster analysis without considering the variable honey production.

\begin{tabular}{|c|c|c|c|c|c|c|}
\hline \multirow{2}{*}{ Etapa } & Combinado & Combinado & \multirow{2}{*}{ Distância } & Etapa prévia & Etapa prévia & \multirow{2}{*}{$\begin{array}{c}\text { Próxima } \\
\text { etapa }\end{array}$} \\
\hline & Cluster 1 & Cluster 2 & & Cluster 1 & Cluster 2 & \\
\hline 1 & 3 & 4 & 15.9857 & 0 & 0 & 2 \\
\hline 2 & 2 & 3 & 16.378 & 0 & 1 & 3 \\
\hline 3 & 2 & 5 & 33.6746 & 2 & 0 & 4 \\
\hline 4 & 1 & 2 & 42.0371 & 0 & 3 & 0 \\
\hline
\end{tabular}


Tabela 11. Resultados da análise de agrupamento considerando as variáveis de produção de mel.

Table 11. Results of cluster analysis considering variables production of honey.

\begin{tabular}{|c|c|c|c|c|c|c|}
\hline Etapa & $\begin{array}{c}\text { Combinado } \\
\text { Cluster } 1\end{array}$ & $\begin{array}{c}\text { Combinado } \\
\text { Cluster } 2\end{array}$ & Distância & $\frac{\text { Etapa prévia }}{\text { Cluster } 1}$ & $\frac{\text { Etapa Prévia }}{\text { Cluster } 2}$ & $\begin{array}{c}\text { Próxima } \\
\text { etapa }\end{array}$ \\
\hline 1 & 2 & 3 & 16.5011 & 0 & 0 & 2 \\
\hline 2 & 2 & 4 & 17.3703 & 1 & 0 & 3 \\
\hline 3 & 2 & 5 & 33.6812 & 2 & 0 & 4 \\
\hline 4 & 1 & 2 & 46.0782 & 0 & 3 & 0 \\
\hline
\end{tabular}

de mel, além das diferentes áreas de uso da terra. Os resultados são apresentados a seguir na Tabela $11 \mathrm{e}$ na Figura 5.

A principal diferença entre a primeira e a segunda análise foi detectada em relação ao apiário 4. Na primeira análise, sem considerar a variável de produção de mel, o dendrograma evidenciou certa distância entre o grupo (cluster) formado pelos apiários 3 e 4 com o apiário 2. Na segunda análise, como pode ser observado na Figura 5, incluindo a variável de produção de mel, o dendrograma resultou no agrupamento entre os apiários 2 e 3 e, posteriormente, com o apiário 4 . Na primeira análise, sem considerar as variáveis reais de produção média de cada apiário, a análise realizada utilizou apenas as componentes de uso e cobertura da terra num raio de proximidade máxima de $1,5 \mathrm{~km}$, as quais caracterizam as condições locais para a produção de mel para cada apiário.

Desta forma, os resultados apresentados pela análise de agrupamento no primeiro dendrograma (Figura 4) indicam que as condições para a produção de mel nos apiários 2, 3 e 4 são semelhantes. Diversamente, na segunda análise, considerandose a inclusão das variáveis reais de produção média obtidas em cada apiário, verifica-se um aumento das distâncias entre as médias dos agrupamentos caracterizados pelos apiários 2 e 3 e o apiário 4, uma inversão na ordem dos agrupamentos. A princípio, o que explicaria a diferença detectada entre o grupo formado pelos apiários 2 e 3 e o apiário 4 estaria relacionado aos diferentes usos da terra, os quais contêm potenciais distintos de flora apícola em diferentes raios de proximidade do apiário. Destacase a relativa proximidade física entre os apiários 1 e 4, embora não ocorram sobreposições do raio de influência destes apiários. Desta forma, o que pode explicar as semelhanças de alta produção seria a ocorrência de espécies de alto potencial apícola na região que envolve ambos os apiários. Os apiários 1 e 5 apresentaram maior produção e alta similaridade em virtude da pequena distância entre os agrupamentos. Isto pode ser explicado pela presença de Eucalyptus sp. num raio de $500 \mathrm{~m}$ em ambas as áreas. $\mathrm{O}$ agrupamento formado pelos apiários 1 e 5 se diferencia dos demais pela presença de Eucalyptus sp. em ambos os apiários, em distância de até $500 \mathrm{~m}$. Na região de influência do apiário 1 , há ocorrência de Eucalyptus sp., o que provavelmente explica a maior produção.

Áreas mais extensas de floresta secundária no local de influência do apiário 5 podem explicar a maior distância desta área para o agrupamento formado pelos apiários 2, 3 e 4 .

\section{CONCLUSÕES}

A interpretação e a vetorização sobre tela, seguidas da classificação de uso da terra com imagens de 5 metros de resolução espacial, possibilitaram a discriminação de dois estratos florestais (estágio inicial e secundário da Floresta Ombrófila Mista), com grande potencial apícola;

A análise descritiva do uso e da cobertura da terra do entorno dos cinco apiários, nas três diferentes faixas definidas pelos raios de proximidade, permitiu verificar diferenças de potenciais de floras apícolas em reflorestamento de Eucalyptus sp., flora urbana, agrícola e estágios inicial e secundário da Floresta Ombrófila Mista;

A inclusão da variável produção média de mel na aplicação da análise de agrupamento demonstrou alteração do grau de similaridade para as condições de 
produção, pois, na primeira análise, sem considerar a variável de produção de mel, foi verificada certa distância entre o grupo (cluster) formado pelos apiários 3 e 4 com o apiário 2, enquanto na segunda análise, incluindo a variável produção de mel, observou-se maior similaridade entre os apiários 2 e 3 e, posteriormente, com o 4;

As análises de agrupamento realizadas antes e após a inclusão da variável produção de mel identificaram diferenças, detectadas na formação dos clusters, o que evidencia que foi possível estabelecer relações entre as variações de uso da terra e consequente flora apícola, principalmente florestal, tanto nativa quanto de reflorestamento, do entorno dos cinco apiários, considerando diferentes raios de proximidade, e suas produções médias de mel.

\section{STATUS DA SUBMISSÃO}

Recebido: 09/04/2012

Aceito: $02 / 02 / 2013$

Publicado: 28/02/2013

\section{AUTOR(ES) PARA CORRESPONDÊNCIA}

\section{Paulo Costa de Oliveira Filho}

Departamento de Engenharia Ambiental, Universidade Estadual do Centro-Oeste UNICENTRO-PR, Rod. PR-153, Km 07, Riozinho, CP 21, CEP 84500-000, Irati, PR, Brasil e-mail: paulocostafh@gmail.com

\section{REFERENNCIAS}

Barbosa AL, Pereira FM, Vieira Neto JM, Rêgo JGS, Lopes MTR, Camargo RCR. Criação de Abelhas: apicultura. Brasília: Embrapa Informação Tecnológica, 2007. v. 2500, 113 p.

Freitas BM. Flora apícola: Volume, concentração e açúcar total do néctar secretado por flores de distintos materiais genéticos de cajueiro (AnacardiumoccidentaleL.). In: Anais da XXXIII Reunião Anual da Sociedade Brasileira de Zootecnia; 1996, Fortaleza. Fortaleza: SBZ; 1996. v. 2, p. 395-397

Moita Neto JM, Moita GC. Uma Introdução á Análise Exploratória de Dados Multivariados. Química Nova 1998; 21(4): 467-469. http://dx.doi.org/10.1590/ S0100-40421998000400016

Pegoraro A, Ziller SR. Valor Apícola das Espécies Vegetais de duas Fases Sucessionais da Floresta Ombrófila Mista, em União da Vitória Paraná - Brasil. Boletim de Pesquisa Florestal 2003; (47): 69-82.

Rodrigues ACM. Mapeamento Multitemporal do uso e cobertura do solo do municípiode São Sebastião-SP, utilizando técnicas de segmentação e classificação de imagens TMLandsate HRV-SPOT. São José dos Campo: INPE; 2000. 94 p. (INPE-7510-PUD/39).

Wiese H. Nova Apicultura. Porto Alegre: Leal; 2000. 253 p.

Wolf LF. Aspectos físicos e ecológicos a serem considerados para a correta localização de apiários $e$ instalação das colméias para a apicultura sustentável na região sul do Brasil. Pelotas: Embrapa Clima Temperado; 2008. 47 p. (Embrapa Clima Temperado. Documentos, n. 238). 